\title{
Intestinal Pseudo-obstruction: Initial Manifestation of Systemic Lupus Erythematosus
}

\author{
Jaeyeon Kim and Nayoung Kim* \\ Division of Gastroenterology, Department of Internal Medicine, Seoul National University Bundang Hospital, Seongnam, Gyeonggi-do, Korea
}

A 20-year-old man was hospitalized for 2 months after the onset of vomiting, cramping abdominal pain and dysuria. He had been diagnosed as IgA nephropathy 4 months ago. His mother was recently diagnosed as systemic lupus erythematosus (SLE). Physical examination revealed hypoactive bowel sounds and distended abdomen with diffuse tenderness. There was no rash on

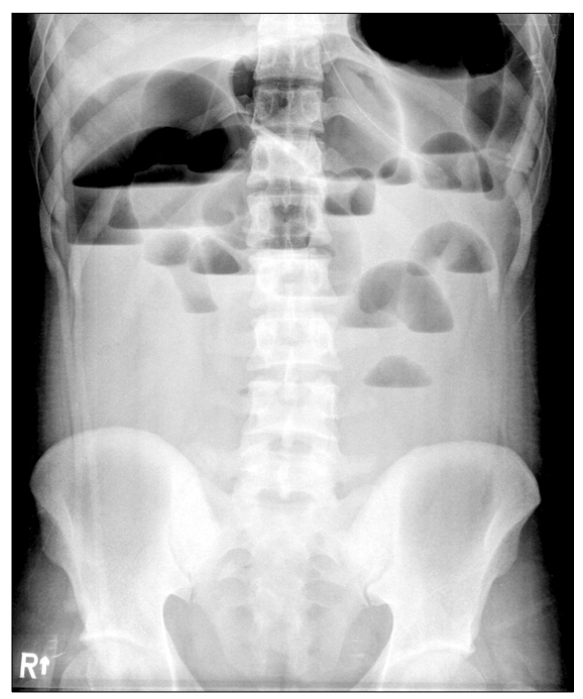

Figure 1. Simple abdominal erect view. Simple abdominal erect film shows extensive dilatation of the small bowel and multiple air-fluid levels. the face and body. The laboratory investigations showed hemoglobin $11.2 \mathrm{~g} / \mathrm{dL}$, leukocyte $10,500 / \mu \mathrm{L}$, platelet $160,000 / \mu \mathrm{L}$ and albumin $3.2 \mathrm{~g} / \mathrm{dL}$. Antinuclear antibody (titer of 1:320 with speckled pattern), anti-Sm and ribonucleotide protein antibodies were positive. The 24 hour urine protein was $1,100 \mathrm{mg} /$ day. Abdominal X-ray demonstrated multiple air-fluid levels of small bowel (Fig. 1). Abdominal CT showed fluid-filled dilatation of small bowel, bilateral hydronephrosis and thickened bladder wall. There was no abnormality on esophagogastroduodenoscopy and colonoscopy. Anorectal manometry showed decreased anal sphincter pressure and intact anaorectal inhibitory reflex.

He was treated with empirical prednisolone $30 \mathrm{mg} /$ day for 3 days but abdominal pain was worsened and plain X-ray showed aggravation of ileus. To find out the underlying cause of intestinal pseudo-obstruction (IPO), subtotal colectomy was performed. Grossly there was no mass, ulcer or mechanical obstruction. Histopathology demonstrated diffuse muscular degeneration with little vasculitis suggestive of SLE (Fig. 2). Steroid and azathiopurine were started after surgery and he became well.

After IPO in SLE was first described in 1993, ${ }^{1}$ few cases have been reported thereafter. ${ }^{2-4}$ As in this case, IPO may appear as the initial presentation of $\mathrm{SLE}^{2}$ and be associated with interstitial cystitis. ${ }^{3-5}$ The pathophysiology of IPO in SLE is dysmotility of the intestinal muscle, caused by neuropathy, vasculitis or primary myopathy. ${ }^{3-5}$ As IPO usually respond to high-dose ste-

Received: September 12, 2011 Revised: September 19, 2011 Accepted: September 20, 2011

(c) This is an Open Access article distributed under the terms of the Creative Commons Attribution Non-Commercial License (http://creativecommons. org/licenses/by-nc/3.0) which permits unrestricted non-commercial use, distribution, and reproduction in any medium, provided the original work is properly cited.

*Correspondence: Nayoung Kim, MD

Department of Internal Medicine, Seoul National University Bundang Hospital, 300 Gumi-dong, Bundang-gu, Seongnam, Gyeonggi-do 463-707, Korea

Tel: +82-31-787-7008, Fax: +82-31-787-4051, E-mail: nayoungkim49@empal.com

Financial support: None.

Conflicts of interest: None. 

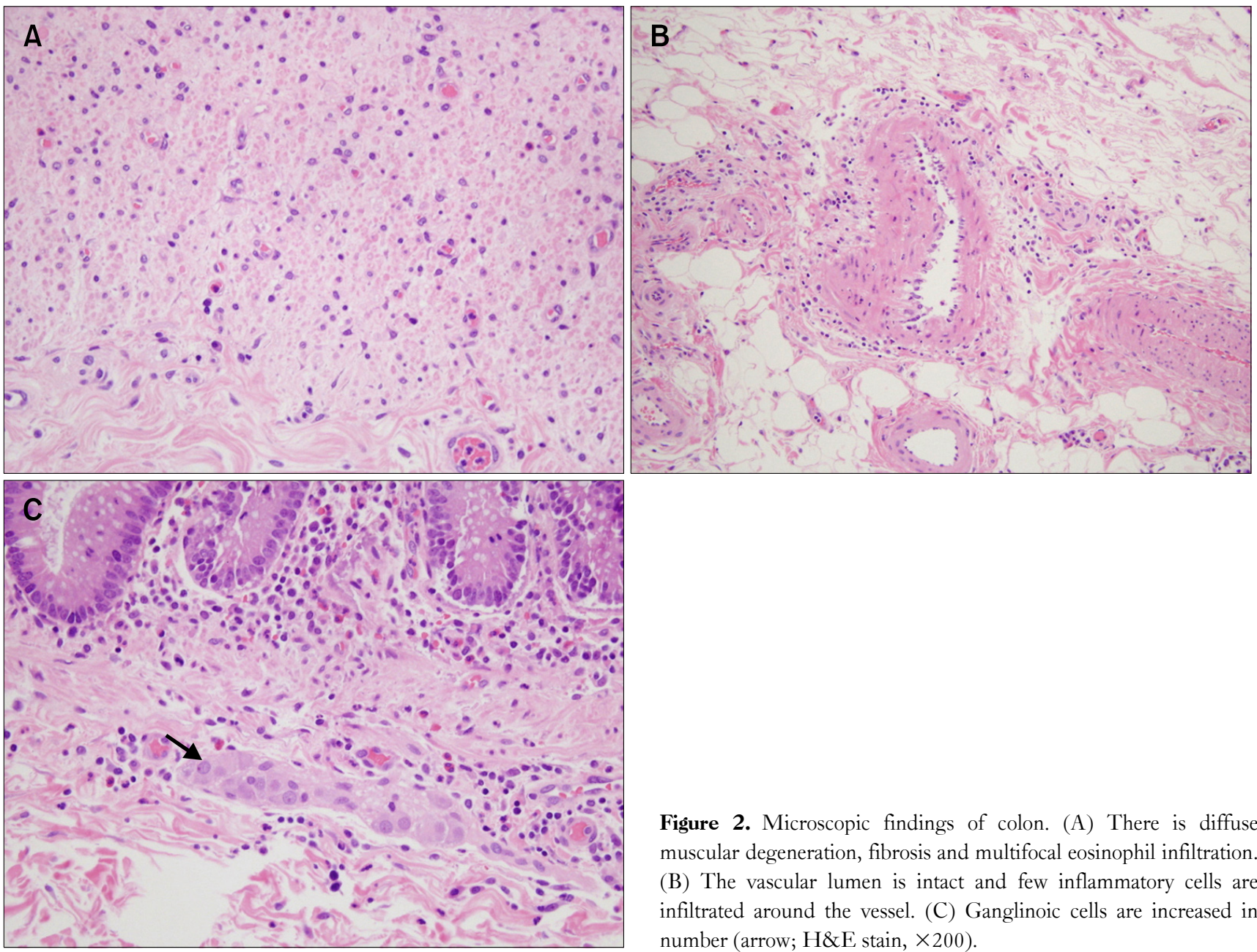

Figure 2. Microscopic findings of colon. (A) There is diffuse muscular degeneration, fibrosis and multifocal eosinophil infiltration. (B) The vascular lumen is intact and few inflammatory cells are infiltrated around the vessel. (C) Ganglinoic cells are increased in number (arrow; H\&E stain, $\times 200$ ).

roid and additional immunosuppressant, early diagnosis and timely initiation of treatment are important to avoid unnecessary surgery.

\section{References}

1. Cacoub P, Benhamou Y, Barbet P, et al. Systemic lupus erythematosus and chronic intestinal pseudoobstruction. J Rheumatol 1993;20:377-381.

2. Nguyen $\mathrm{H}$, Khanna N. Intestinal pseudo-obstruction as a presenting manifestation of systemic lupus erythematosus: case report and re-

view of the literature. South Med J 2004;97:186-189.

3. Ceccato F, Salas A, Góngora V, et al. Chronic intestinal pseudo-obstruction in patients with systemic lupus erythematosus: report of four cases. Clin Rheumatol 2008;27:399-402.

4. Malaviya AN, Sharma A, Agarwal D, et al. Acute abdomen in SLE. Int J Rheum Dis 2011;14:98-104.

5. Chng HH, Tan BE, Teh CL, Lian TY. Major gastrointestinal manifestations in lupus patients in Asia: lupus enteritis, intestinal pseudo-obstruction, and protein-losing gastroenteropathy. Lupus 2010; 19:1404-1413.

6. Connor FL, Di Lorenzo C. Chronic intestinal pseudo-obstruction: assessment and management. Gastroenterology 2006;130(2 suppl 1): S29-S36. 